\title{
Please lend a hand
}

\author{
R Knight Steel
}

J R Soc Med 2007; 100:528-528

Dear Reader:

It would be quite understandable if you decided you didn't wish to do so. But perhaps you would be willing to lend a hand. So, as an American physician, I am writing to you at this time to seek your support and wisdom as we face a crisis on the other side of the pond. I am referring, of course, to asking you to offer your assistance with the matter of revamping the health-care system in the United States. Granted it's not a small task, but equally clearly it is one that needs doing.

To begin might I suggest that you take a look at the population whom those of us in medicine are trying to serve. Assuredly, given my 67 years and my long history in geriatric medicine, I have a bias. Nonetheless you might not be aware of the fact that those aged 65 and over, rather arbitrarily diagnosed as elderly by Medicare - the government programme that pays for acute care in the elderlymake up about $13 \%$ of our population. Yet they utilize a markedly disproportionate percentage of health-care resources. For example, at our hospital, which has an annual budget in excess of $\$ 1,000,000,000$, this segment of the population now accounts for more than $40 \%$ of beddays and this percentage is rising annually. In the USA the elderly occupy about $90 \%$ of all long-term care beds, of which there are now more than there are acute care beds.

Surely, dear Reader, as is so true in your country as well, you are aware of the fact that the baby boomers are now joining the Medicare-eligible crowd in large numbers. Social Security, the government retirement programme, is threatening to collapse and Medicare is looking for ways to control costs. Yet the American health-care system turns out fewer than 300 geriatricians a year. With only the briefest of glances it can be seen that this is in no small part because of the perverse incentives in the present-day system.

Here I am referring to the exorbitant differences in the rates of reimbursement among different specialties. As background I would remind you that our health-care system is designed to fit in with the American model of private enterprise. In the United States if you carry out a procedure, which you may well order yourself, you are paid far more on an hourly basis than when you are taking the history and carrying out the physical examination that suggests that that procedure is indicated. For example, an ophthalmologist removing cataracts might expect to generate eight times or more the hourly income a geriatrician might expect to make caring for elders with multiple chronic conditions. I won't elaborate here on my belief that under most circumstances this ophthalmic procedure might be carried out just as well by a welltrained technician. Perhaps I am biased, but it cannot be denied that the discrepancies in potential income have a huge effect on the choices of graduating physicians.

Consider in your mind the graduating physician. Unlike the situation in the UK, the cost of obtaining a medical education falls to the student or the student's parents. A student who followed my path, travelled so many years ago, and went to Yale University (present-day undergraduate annual tuition, room and board $\$ 45,000$, plus health coverage of $\$ 1632$ for each of four years) and Columbia University for medical school for four years (first year tuition, room and board $\$ 61,218$, increasing with each year) could expect to spend approximately $\$ 500,000$ for this educational experience. Most would take out loans, and should two graduates have the desire to become husband and wife they might well begin their journey in life together with a debt approaching $\$ 1,000,000$. Is it no wonder that ophthalmology looks more appealing than geriatric medicine to the graduate laden with so much baggage?

And so I am coming to you on bended knee. Perhaps you could advise those of us who speak the same tongue how we might learn from your experience. At the same time, feel free to learn from ours! As you debate the merits of private enterprise within the national health system - be forewarned.

Competing interests None declared. 